\title{
Productivity Analysis Comparison of Different Types of Earthmoving Operations by Means of Various Productivity Measurements
}

\author{
Seungwoo Han
}

Associate Professor, School of Architecture, Inha University, Korea

\begin{abstract}
Researchers and site engineers in construction have tried to develop appropriate methods of productivity measurements. Even though many methods have been released in academia and industry, they seldom are able to select the optimized method while considering various site conditions. This study was developed from a previous study which presented the quantified productivity differences on one specific operation, that of the conventional earthmoving operation. This study suggested more consistent results for productivity differences by various methods while focusing on two different operations; the conventional and the GPSbased system. This study verified the findings from a previous study whereby results from a deterministic method and an actual measurement yield the highest values and the lowest values, respectively. It was also found that the quantified differences were mostly within $10 \%$ of the range of productivity loss in the deterministic measurement, which was illustrated in the literature. Additional statistical verification showed that the differences were mostly within $95 \%$ of the confidence intervals. It is expected that this study will provide researchers in academia with basic guidelines for developing appropriate methods for performance measurements. This study also assists site engineers in the construction industry to predict productivity and to convert results to more realistic values by using methods other than actual measurements.
\end{abstract}

Keywords: productivity; earthmoving; GPS; deterministic; simulation

\section{Introduction}

One of the key activities for a successful construction project is to evaluate construction performances which have been mostly measured using two criteria; productivity and unit costs (Schaufelberger 1999; Nunnally 2000).

Measuring productivity is a fundamental activity for the establishment of appropriate construction plans and resource utilization prior to actual construction operations. Productivity measurement functions as an indicator of the basic status of the construction operation and provides actual data for productivity improvement and for productivity prediction in similar operations in the future (Han and Lee 2008). Various methods for productivity measurements have been introduced and developed in academia such as deterministic model-based measurement, simulation-based measurement, queuing theory-based measurement, and actual measurement (Halpin and Riggs 1992). These four productivity measurement measures were usually utilized in academic areas for

*Contact Author: Seungwoo Han, Associate Professor, Inha University, 253 Yonghyun-Dong, Nam-Gu, Incheon, 402-751 Korea

Tel: +82-32-860-7595 Fax: +82-32-866-4624

E-mail: shan@inha.ac.kr

(Received April 8, 2009 ; accepted February 1, 2010) evaluating construction performances. The difficulty in the application of these methods in actual operations creates a need for careful investigations of comparisons of these four methods and analysis of different types of construction operations in practice (Han 2005; Han and Lee 2008). Productivity comparisons of an identical operation obtained by various methods present the basic characteristics and result analysis of each method according to quantified differences (Han and Lee 2008). Furthermore, a productivity comparison of different operations by various methods would provide an opportunity to prove findings of basic characteristics and results of each method and to give wide applications to more varied construction operations.

Han and Lee (2008) conducted a previous study that involved the application of four different productivity measurements on identical operations of conventional earthmoving. As described in this previous study, these four methods for productivity measurement presented not only basic characteristics and practical application issues but also quantified differences in the results. Further study is required to determine whether the findings from the previous study (Han and Lee 2008) are consistently found in different operations under different situations.

Accordingly, the objective of this study is to verify the quantified differences of four productivity 
measurements mostly developed in academia concerning different operations. Two operations in earthmoving were selected for a comparison of results of productivity measurements as different operations within the scope of this study; 1) Conventional, and 2) GPS-based systems. The reason for the selection of an earthmoving operation was because it is the most fundamental operation in building and civil construction projects. Furthermore, compared to other operations in construction, the composition of construction resources for an earthmoving operation is sufficiently simple so that quantified differences were clearly identified and analyzed.

Quantified differences calculated by four various productivity measurements on two different types of operations allow researchers and practitioners in construction to select an appropriate method among these methods considering the particular situations on job sites and understanding the basic variance ranges in cases where other productivity measurements are used.

\section{Productivity Measurement Methods}

As stated in the previous study by Han and Lee (2008), there are four methods in construction among many productivity measurement methods which have been developed.

A deterministic model-based measurement is commonly employed with easy and simple practical applications. According to many studies (Halpin and Riggs 1992; Schaufelberger 1999; Nunnally 2000; Schexnayder and Mayo 2004; Halpin 2006), this method was implemented by simple calculation of the productivity of many construction operations based on the equipment characteristics under the particular construction situation on job sites provided by most manufacturers or the historical construction data collected. Fixed or constant values as duration information were applied in this method. However, it revealed that the adoption of fixed or constant duration of each activity was not able to reflect any variability in the task duration (Han and Lee 2008).

It has been pointed out that fixed time duration used in the deterministic model could not resolve bunching effects generally witnessed in the construction operation (Halpin and Riggs 1992). The efforts made to overcome this problem in the deterministic model resulted in the queuing modelbased measurement originally created in industrial processes of construction. The original queuing model in industrial processes was only available in a twolink system; a processor responding to trucks and calling units responding to loaders or excavators in an earthmoving operation (Halpin and Riggs 1992; Guo 2007). Practical application using this model is limited in construction due to the constrained availability of only a two-link system. However, it provides quantified bunching effects that cannot be resolved by a determinist model (Han and Lee 2008).
Compared with the deterministic and queuing models, a simulation-based measurement presents excellent outcomes that reflect normal situations where the randomness of cycle time is considered. The influence of random durations on the movement of resources causes various units to become bunched together and consequently there is a rush to arrive at and overload work tasks. The simulation methodology which has been extensively developed and broadly used as a management tool within the manufacturing and business industries was modified and developed for construction application as the CYCLONE (CYCLic Operation Network) system approach in the early 1970s (Halpin 2006; Han and Lee 2008). This system was further developed into the MicroCYCLONE, a microcomputer version of CYCLONE demonstrating the potential for the modeling and simulation of repetitive construction processes. Many studies have been conducted based on MicroCYCLONE methodology for measurement, evaluation, improvement, and prediction of construction performances (AbouRizk and Halpin, 1992; Kannan, 1999; Wang and Halpin, 2004; Han and Halpin, 2005; Han et al., 2006; Han et al. (2008); and Han and Lee, 2008). While the simulation-based measurement is the most appropriate method to illustrate the actual construction situation prior to the actual operation, the use of this method is very limited due to the shortage of knowledge of computer programming and modeling (Han and Halpin 2005; Han and Lee 2008).

The actual productivity measurement is regarded as the most difficult method to use even though it provides actual productivity. This is due to the requirement for all event times to be recorded and actual productivity to be measured by human beings on job sites. Accordingly, the reliability of the results obtained by this method is diverse rather than stable, depending on who is involved and what specific technique is used for measurements (Han 2005; Han and Halpin 2005; Han et al. 2006; Han et al. 2008; Han and Lee 2008).

\section{Basic Operational Concepts of the Conventional and GPS-based Earthmoving Operations}

Earthmoving, a fundamental operation in construction, is divided into two types of systems; the conventional and the GPS-based systems as GPS technology was applied to construction over a decade ago (Han et al. 2006; Han et al. 2008).

The conventional system requires additional activities such as surveying, installing stakes, resetting stakes knocked down during operations, and reworks which are frequently required to basic activities such as preparation, loading, hauling, dumping and spreading (Hajjar and AbouRizk 1997; Han et al. 2006). These additional activities including reworks cause a serious delay to work time and significantly reduce productivity. Referring to the measuring volume of the moved earth, operators of hauling equipment would 
count the number of traveling times in one working day. These numbers functioned as raw data to measure daily productivity and calculate the total volume of the moved earth per day (Nichols and Day 1999; Han et al. 2006; Han et al. 2008; Han and Lee 2008).

The GPS-based system was first introduced in construction with "stake-less earthmoving". GPS signals are transmitted from satellites to GPS antenna and a receiver. These signals are interpreted as resulting positions by a computer unit. The interpreted signal provides the real-time location of the target equipment on a map displayed as the Graphical User Interface (GUI) on the machine cap system (Koehrsen et al. 2001; Han et al. 2006). Koehrsen et al. (2001) presented a procedure for an earthmoving operation by the GPS-based system. According to their study, the operator is aware of the position of the equipment under his control and recognizes the amount of cut and fill volumes associated with precise elevations in real time. Compared to the conventional system, the GPS-based system consequently provides increased productivity by removing surveying and other related activities and enhances the quality of work reducing reworks. The GPS-based system is currently being used in large-scale civil projects such as highway construction.

\section{Data Collection}

The result distinction by four different productivity measurements for the conventional system was presented in the previous study by Han and Lee (2008). Three earthmoving projects where the GPS system was used were additionally selected. While a twolink system comprised of excavators and trucks was selected in the conventional system, a three-link system with excavators, dozers, and trucks was selected in the GPS-based system. This difference is derived from the fact that the GPS system in commercial markets was generally installed in dozers. A total of five conventional earthmoving projects and a total of three GPS-based earthmoving projects were selected where construction raw data was collected for this study. A total of 20 and 16 separate hourly datasets in the conventional and the GPS-based system, respectively, were achieved through four to five hours over two to three consecutive days at each jobsite (Han 2005; Han and Halpin 2005; Han et al. 2008).

All activities and specific durations of each physical activity were measured by stopwatch and video-taping analysis. Other data related to non-physical activities were collected through site observations and interviews with site personnel (Han 2005; Han et al. 2008).

Tables 1 . and 2. show the basic descriptions of earthmoving projects selected for data collection and summary of data characteristics collected from the earthmoving projects.

The basic format of the collected datasets is shown in Table 3; one sample of the collected datasets from
Table 1. Basic Descriptions of Construction Jobsites (Han et al. 2008)

\begin{tabular}{cccc}
\hline System & PJ. & Fleet Organization & $\begin{array}{c}\text { Two-way haul } \\
\text { distances (km) }\end{array}$ \\
\hline Conv. & C1 & 1 Excavator / 7 Trucks & 4.8 \\
& C2 & 1 Excavator / 4 Trucks & 25.4 \\
& C3 & 1 Excavator / 9 Trucks & 7.7 \\
& C4 & 1 Excavator / 2 Trucks & 1.8 \\
& C5 & 1 Excavator / 7 Trucks & 15.1 \\
\hline \multirow{2}{*}{ GPS } & G1 & 1 Excavator / 1 Dozer \\
& G2 & 1 Excavator / 1 Dozer & 26.1 \\
& 7 Trucks & 16.9 \\
& G3 & 1 Excavator / 1 Dozer & 3.9 \\
& 4 Trucks
\end{tabular}

Note: Conv., the conventional system

GPS, the GPS-based system

Table 2. Description of the Collected Data (Han et al. 2008; Han and Lee 2008)

\begin{tabular}{cccc}
\hline \multicolumn{2}{c}{ Site Observations } & Field \\
$\begin{array}{c}\text { Stopwatch } \\
\text { Analysis with } \\
\text { Videotaping }\end{array}$ & Interviews & $\begin{array}{c}\text { Measurement } \\
\text { Calculation }\end{array}$ & \\
\hline $\begin{array}{c}\text { Machine break } \\
\text { time }\end{array}$ & $\begin{array}{c}\text { Bucket } \\
\text { capacity }\end{array}$ & $\begin{array}{c}\text { Soil } \\
\text { condition }\end{array}$ & $\begin{array}{c}\text { Hauling } \\
\text { speed }\end{array}$ \\
$\begin{array}{c}\text { Resurveying } \\
\text { time }\end{array}$ & $\begin{array}{c}\text { Truck } \\
\text { capacity } \\
\text { Number of } \\
\text { Loading time }\end{array}$ & $\begin{array}{c}\text { Hauling } \\
\text { distance }\end{array}$ & Productivity \\
equipment & & \\
Travel time & $\begin{array}{c}\text { Operators' } \\
\text { experience }\end{array}$ & & \\
Number of & Age of & & \\
loadings & equipment & & \\
& & \\
\hline
\end{tabular}

G1 project where the GPS-based system was used during one hour. Based on the collected datasets, in the next section productivity is measured by four different methods.

\section{Productivity Measurements}

Productivity measurements are conducted based on the collected datasets shown in Table 3. using four different methods.

- Deterministic Model-based Measurement

As stated in the previous study by Han and Lee (2008), the first step of the deterministic model-based productivity measurement is to identify each cycle time of activity by construction equipment. The cycle time of each activity consists of variable times and fixed times. A variable time is regarded as the average time of each cycle of repetitive activities. A fixed time which shows constant values was derived from standard references such as the Caterpillar Operation Handbooks or RS Means. Total productivity based on the deterministic model is calculated by "one divided by cycle times". The procedure for the deterministic model is shown in equations (1) and (2).

Cycle time $=$ Variable times + Fixed times: Equation $(1)$ 
Table 3. Basic Data Format: One of Sample Dataset in Project G1 (Unit: minutes)

\begin{tabular}{cccccccccc}
\hline $\begin{array}{c}\text { Truck } \\
\text { No. }\end{array}$ & Trip & No. & $\begin{array}{c}\text { Truck } \\
\text { Enters } \\
\text { Systems }\end{array}$ & $\begin{array}{c}\text { Service } \\
\text { Completed } \\
\text { Before }\end{array}$ & Delay Time & $\begin{array}{c}\text { Truck Exits } \\
\text { System }\end{array}$ & \multicolumn{2}{c}{ Service Time } & \multicolumn{2}{c}{$\begin{array}{c}\text { Truck } \\
\text { Queue Yes } \\
\text { Seenters }\end{array}$} & $\begin{array}{c}\text { Back Cycle } \\
\text { Time }\end{array}$ \\
\hline 1 & 1 & 0.00 & 0.00 & 0.00 & 1.83 & 1.83 & N/A & 45.05 & 43.22 \\
2 & 1 & 0.00 & 1.83 & 1.83 & 4.23 & 2.40 & N/A & 54.00 & 49.77 \\
3 & 1 & 0.00 & 4.23 & 4.23 & 6.92 & 2.68 & N/A & 55.88 & 48.97 \\
4 & 1 & 3.75 & 6.92 & 3.17 & 8.47 & 1.55 & N/A & 58.02 & 49.55 \\
5 & 1 & 4.72 & 8.47 & 3.75 & 11.37 & 2.90 & N/A & 60.80 & 49.43 \\
6 & 1 & 14.80 & 11.37 & $(3.43)$ & 16.38 & N/A & 1.58 & 63.58 & 47.20 \\
7 & 1 & 21.12 & 16.38 & $(4.73)$ & 22.77 & N/A & 1.65 & 65.77 & 43.00 \\
8 & 1 & 23.20 & 22.77 & $(0.43)$ & 24.75 & N/A & 1.55 & 66.05 & 41.30 \\
9 & 1 & 39.85 & 24.75 & $(15.10)$ & 41.67 & N/A & 1.82 & 83.03 & 41.37 \\
10 & 1 & 43.32 & 41.67 & $(1.65)$ & 44.72 & N/A & 1.40 & 86.20 & 41.48 \\
1 & 2 & 45.05 & 44.72 & $(0.33)$ & 46.68 & N/A & 1.63 & 89.00 & 42.32 \\
2 & 2 & 54.00 & 46.68 & $(7.32)$ & 55.58 & N/A & 1.58 & 93.82 & 38.23 \\
3 & 2 & 55.88 & 55.58 & $(0.30)$ & 57.58 & N/A & 1.70 & 95.35 & 37.77 \\
4 & 2 & 58.02 & 57.58 & $(0.43)$ & 59.75 & N/A & 1.73 & 97.93 & 38.18 \\
\hline
\end{tabular}

Productivity $=\frac{60(\min . / \mathrm{hr} .)}{\text { cycle time }(\mathrm{min} . / \mathrm{hr} .)}:$ Equation $(2)$

\section{- Queuing Theory-based Measurement}

The queuing theory developed in the manufacturing industry has been applied to construction in order to resolve the problem caused by the deterministic model whereby it would not reflect bunching effects. Considering that bunching effects in construction are frequently witnessed in job sites, a queuing theorybased measurement enables the provision of more realistic results than does the deterministic model.

The text by Halpin and Riggs (1992) suggested that the productivity based on a queuing theory is calculated as follows.

Productivity $=(\mathrm{PI}) \times \mathrm{L} \times \mathrm{C} \times \mu$ : Equation (3)

where,

PI = Productivity Index (i.e., percent of the time of the system contains units that are loading).

$\mathrm{L}=$ Period of time considered

$\mathrm{C}=$ Capacity of the unit loaded

$\lambda=1 /$ the average time a unit stays outside the system shown in Table 4.

$\mu=$ Processor rate $=1 /$ the average service time shown in Table 4.

Note that in equation (3), the value of $\lambda$ is calculated in arrivals per hour and $\mu$ is calculated in loads per hour. The mean service time in minutes for $\mu$, denoted as $\mathrm{T}_{\mathrm{s}}$ shown in Table 4., is calculated from the summation of service times divided by the total number of trips per hour. The mean arrival time in minutes for $\lambda$, denoted as $T_{a}$ shown in Table 4., is calculated from the summation of back cycle times divided by the total number of trips per hour. The PI value shown in equation (3) is derived from Queuing nomographs shown in the text by Halpin and Riggs (1992) using the utilization factor $(\lambda / \mu)$ (Han 2005; Han and Lee 2008).

Hourly productivity by queuing theory-based measurement is calculated by equation (3) and information in table 3 , and one sample dataset in project $\mathrm{G} 1$ is as follows:

$$
\begin{aligned}
\text { Productivity } & =(\mathrm{PI}) \times \mathrm{L} \times \mathrm{C} \times \mu \\
& =0.53 \times 1 \times 1 \times 25.60 \\
& =13.57 \text { cycles } / \mathrm{hr} .
\end{aligned}
$$

- Simulation-based Measurement

Simulation methodology which has been attributed in many applications in construction is currently used for various functions such as measuring productivity, evaluating performances, and predicting productivity. Figs.1. and 2. show each sample of project $\mathrm{C} 3$ of the conventional and project G1 of the GPS-based system, respectively.

The symbols used in Figs.1. and 2. are CYCLONE modeling elements as described by Halpin and Riggs (1992). Basic descriptions of each element are shown in Table 5., excerpted in the text by Halpin and Riggs (1992).

As illustrated in Figs.1. and 2., the GPS-based system employed one additional dozer in the fleet management compared to the conventional system. This shows that the GPS equipped dozer was involved in earthmoving with an excavator and trucks. The nodes with the probabilistic branching indicate that the allotted resources on these nodes could proceed either way following determined probabilities. The probability of checking shown at node 3 is assumed to be 0.0001 , which is initially designed as the minimum value in the probabilistic function, implying that the checking activity at node 3 seldom occurred during site observations. However, other datasets in the conventional earthmoving projects show a varied range from 0.0001 to 0.2 as the probability of this node. 
Table 4. Information for Calculation of $\lambda$ and $\mu$; One of the Sample Datasets in Project G1 (Unit: minutes)

\begin{tabular}{|c|c|c|c|c|c|c|}
\hline Truck No. & Trip No. & $\mathrm{T}_{\mathrm{a}}$ & $\lambda$ & Load & $\mathrm{T}_{\mathrm{s}}$ & $\mu$ \\
\hline 1 & 6 & 40.92 & 1.47 & 6 & 2.06 & 29.11 \\
\hline 2 & 6 & 33.86 & 1.77 & 6 & 2.31 & 26.02 \\
\hline 3 & 6 & 39.78 & 1.51 & 6 & 2.30 & 26.06 \\
\hline 4 & 6 & 40.43 & 1.48 & 6 & 2.05 & 29.31 \\
\hline 5 & 6 & 39.71 & 1.51 & 6 & 2.58 & 23.28 \\
\hline 6 & 6 & 47.30 & 1.27 & 6 & 2.58 & 23.29 \\
\hline 7 & 6 & 58.41 & 1.03 & 6 & 2.54 & 23.59 \\
\hline 8 & 6 & 47.71 & 1.26 & 6 & 2.73 & 21.98 \\
\hline 9 & 5 & 37.91 & 1.58 & 5 & 2.01 & 29.85 \\
\hline \multirow[t]{2}{*}{10} & 5 & 38.25 & 1.57 & 5 & 2.29 & 26.24 \\
\hline & $\sum=58$ & Avg. $\left(\mathrm{T}_{\mathrm{a}}\right)=42.43$ & Avg. $(\lambda)=1.41$ & $\sum=58$ & Avg. $\left(T_{s}\right)=2.34$ & Avg. $(\mu)=25.60$ \\
\hline
\end{tabular}

Table 5. CYCLONE Modeling Elements (Halpin and Riggs 1992; Han et al. 2006)

\begin{tabular}{|c|c|c|}
\hline Symbol & Name & Description \\
\hline & NORMAL & Unconstrained in its starting logic and indicates active processing of (or by) resource entities \\
\hline & COMBI & $\begin{array}{l}\text { Logically constrained in its starting logic, otherwise similar to the NORMAL work task } \\
\text { modeling element }\end{array}$ \\
\hline & QUEUE & Represents a queuing up, or waiting for the use of passive state resources \\
\hline & CONSOLIDATE & Used to consolidate flow units at certain points in the system \\
\hline & COUNTER & $\begin{array}{l}\text { Counts the number of times a key unit passes a particular control point in the network model so } \\
\text { that production can be measured }\end{array}$ \\
\hline & $\mathrm{ARC}$ & $\begin{array}{l}\text { Used to model the direction of resource entity flow between the various active-state nodes and } \\
\text { the passive-state nodes }\end{array}$ \\
\hline
\end{tabular}

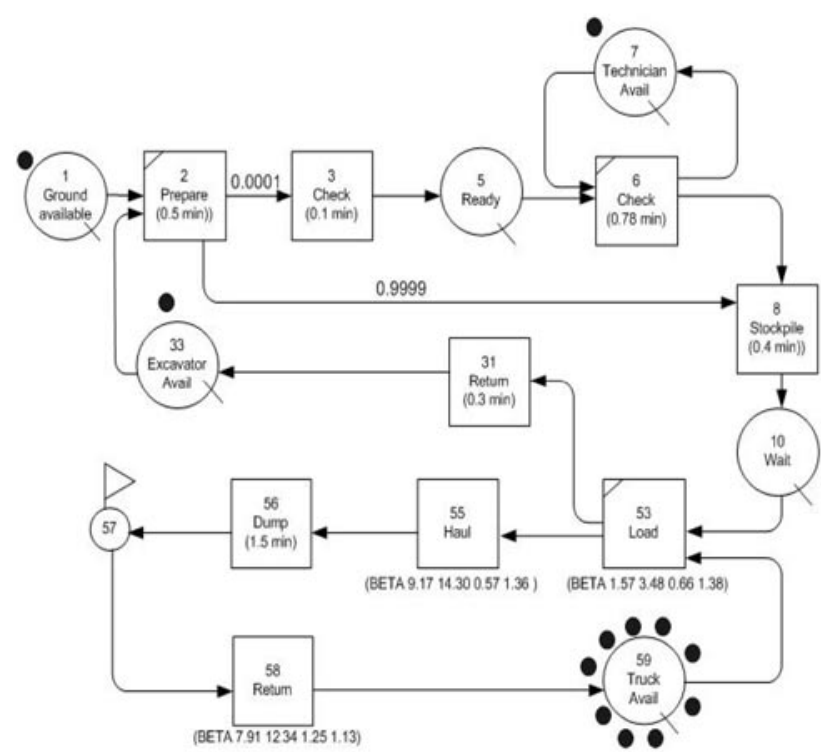

Fig.1. One Sample of Simulation Models for Project C3 for the Conventional System (Han and Lee 2008)

This probability varied considerably depending on the numbers of interruptions due to surveyors who were involved in resurveying for the activity of resetting the grade stakes that were knocked out. Unlike the conventional system, this interruption was not observed in the GPS-based system. This fact was regarded as one of the advantages of the GPS-based system (Han 2005; Han et al. 2006; Han et al. 2008; Han and Lee
2008).

The distribution of durations at nodes 53,55 , and 58 having variable cycle times in Figs.1. and 2. were assumed as beta distributions. AbouRizk and Halpin (1992) recommended the use of beta distributions in modeling random input processes of construction durations for simulation studies because beta distribution can reflect a flexible distribution (Han and Lee 2008). Besides, durations at each node were assumed to be deterministic since significant variances in the durations were not observed in this study.

- Actual Measurement

An actual productivity is normally measured on a daily basis using a cycle counter while recording the number of dumping or specific activities by the operators of trucks. Site managers collect all recorded data from the operators and calculate daily productivity after the completion of one working day. The calculated daily productivity converts to hourly productivity divided by the total working hours per day (Han 2005; Han and Lee 2008).

\section{Comparisons of Results from Various Productivity Measurements}

All methods and procedures presented in both the previous study by Han and Lee (2008) and this present study were equally applied to all datasets of the conventional and the GPS-based systems.

As mentioned earlier, the queue theory-based measurement was limited for practical applications of 


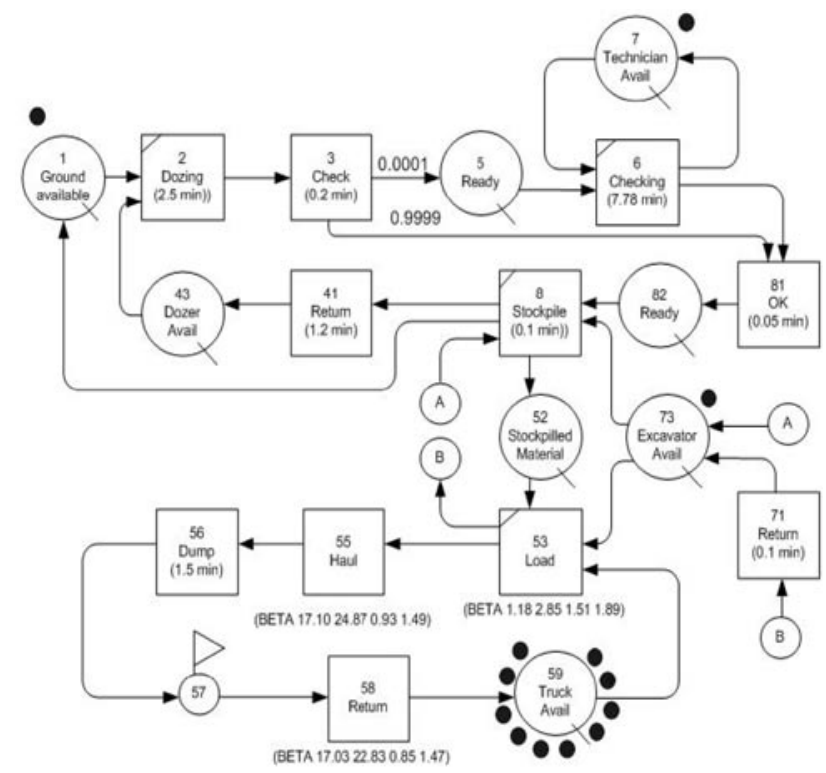

Fig.2. One Sample of Simulation Models for Project G1 for the GPS-based system (Han et al. 2008)

particular cases which break from queue discipline, where all activities interacting in a queuing system are continuously operated without any breakdown. Based on this limitation, it is noted that the queuing model cannot be applied to cases that have interruptions caused by surveyors' re-staking and re-surveying in the conventional system and technicians' checking in the GPS-based system (Halpin and Riggs 1992; Han and Lee 2008). The cases where these interruptions were involved could not be included in comparisons.

Table 6. shows quantified comparisons of productivity measurements in the conventional and the GPS-based systems excluding particular cases presenting the application limitation in the queue theory-based measurement. Rates shown in table 6 indicated the percentage rate of particular results compared to results obtained by actual measurements. The numbers shown in the column of data in table 6 indicate the number of the selected dataset. For instance, Data 3 of project $\mathrm{C} 1$ shown in the first row presents the third dataset in project $\mathrm{C} 1$ where the conventional system was applied.

- Result Comparison on Identical Operation

Quantified results in Table 6. reach similar conclusions as those suggested in the previous study by Han and Lee (2008). In the conventional system, the average value of comparison rates, which are the results obtained by each different productivity measurement compared with those obtained by the actual measurement, yielded $106.23 \%, 104.81 \%$, and $101.71 \%$, by the deterministic model, the simulation model, and the queuing theory, respectively. In the GPS-based system, average rates were shown to be $113.94 \%, 108.91 \%$ and $108.15 \%$. Based on these observations, it is concluded that the deterministic model-based measurement yielded the highest values of productivity. The results of the simulation modelbased measurement followed those of the deterministic model-based measurement, while those of the actual measurement yielded the lowest values of productivity (Han and Lee 2008). This fact is also witnessed not only in the conventional system but also in the GPSbased system.

Halpin (2006) stated that many factors such as bunching in construction operation cause a $10 \%$ productivity loss in the deterministic measurement due to random travel times by earthmoving equipment.

It is noted that productivity loss in deterministic measurement is $5.86 \%(100 \% / 106.23 \%=94.14 \%$;

Table 6. Quantified Comparison of Various Productivity Measurements

\begin{tabular}{|c|c|c|c|c|c|c|c|c|}
\hline \multirow{4}{*}{ Project } & \multirow{4}{*}{ Data } & \multicolumn{7}{|c|}{ Productivity Measurements (Unit: cycles/hr.) } \\
\hline & & \multirow{3}{*}{$\begin{array}{c}\text { Actual } \\
\text { Measurement } \\
\text { Productivity }\end{array}$} & \multirow{3}{*}{$\begin{array}{l}\text { Queuing } \\
\text { Theory } \\
\text { Productivity }\end{array}$} & \multirow{2}{*}{\multicolumn{3}{|c|}{$\begin{array}{c}\text { Simulation } \\
\text { Model }\end{array}$}} & \multirow{2}{*}{\multicolumn{2}{|c|}{ Deterministic Model }} \\
\hline & & & & & & & & \\
\hline & & & & Rates $(\%)$ & Productivity & Rates (\%) & Productivity & $\begin{array}{c}\text { Rates } \\
(\%)\end{array}$ \\
\hline \multicolumn{9}{|c|}{ Conventional system } \\
\hline $\mathrm{C} 1$ & 3 & 24.51 & 24.55 & 100.16 & 26.00 & 106.08 & 26.37 & 107.59 \\
\hline $\mathrm{C} 3$ & 1 & 16.42 & 17.40 & 105.97 & 17.48 & 106.46 & 17.71 & 107.86 \\
\hline 4 & & 18.14 & 18.19 & 100.28 & 18.56 & 102.31 & 18.78 & 103.53 \\
\hline $\mathrm{C} 5$ & 1 & 15.46 & 15.53 & 100.45 & 16.14 & 104.40 & 16.38 & 105.95 \\
\hline \multicolumn{2}{|c|}{ Average } & & & 101.71 & & 104.81 & & 106.23 \\
\hline \multicolumn{2}{|c|}{ Standard deviation } & & & 2.84 & & 1.89 & & 1.99 \\
\hline \multicolumn{9}{|c|}{ GPS-based system } \\
\hline \multirow{6}{*}{ G1 } & 1 & 12.39 & 13.55 & 109.36 & 13.57 & 109.52 & 14.21 & 114.69 \\
\hline & 2 & 12.68 & 13.99 & 110.33 & 14.04 & 110.73 & 14.92 & 117.67 \\
\hline & 3 & 12.35 & 13.51 & 109.39 & 13.62 & 110.28 & 14.43 & 116.84 \\
\hline & 4 & 13.02 & 13.60 & 104.45 & 13.80 & 105.99 & 14.38 & 110.45 \\
\hline & 5 & 13.38 & 13.65 & 102.02 & 13.66 & 102.09 & 14.66 & 109.57 \\
\hline & 6 & 13.09 & 13.57 & 103.67 & 13.69 & 104.58 & 14.06 & 107.41 \\
\hline $\mathrm{G} 2$ & 1 & 13.84 & 15.74 & 113.73 & 15.84 & 114.45 & 16.23 & 117.27 \\
\hline G3 & 4 & 13.64 & 15.31 & 112.24 & 15.50 & 113.64 & 16.05 & 117.67 \\
\hline \multicolumn{2}{|c|}{ Average } & & & 108.15 & & 108.91 & & 113.94 \\
\hline \multicolumn{2}{|c|}{ Standard deviation } & & & 4.26 & & 4.35 & & 4.17 \\
\hline
\end{tabular}


$5.86 \%$ of loss) in the conventional system. The GPS-based system also indicates $12.23 \%$ of loss in the deterministic measurement $(100 \% / 113.94 \%$ $=87.77 \% ; 12.23 \%$ of loss). The results of $10 \%$ of productivity loss by Halpin (2006) were analyzed based on lognormal distribution. If other distributions were considered, slight differences from $10 \%$ would be addressed.

In addition, quantified differences by four productivity measurements are consistent within particular ranges in both systems. It would be useful to obtain information on consistent quantified differences within some range, in order to enable site engineers to make proper operational plans considering these differences and to perform particular actions for counteracting these effects.

\section{- Result Comparison on Different Operations}

A comparison of the results of the conventional and the GPS-based systems revealed that deviations of average values of each measurement to the actual measurement in the conventional system were less than those in the GPS-based system. Although the application of the GPS technology enhances the performance, the deviations of quantified results of productivity measurements were more varied. These facts were due to the following:

- The three-link system in the GPS-based system gives a greater variance on productivity measurements than the two-link system in the conventional system due to the involvement of additional construction equipment

- Hauling times were varied in the GPS-based system due to long haul distance. The broad range of variable times of hauling in the GPS-based system causes such variances.

- Re-staking and re-surveying activities required in the conventional system would deliver greater variances. However, these cases were excluded in table 6 due to no implementation of the queue theory-based measurement.

Verification is also required regarding whether or not the range of quantified differences were normally under confidence levels of $95 \%$ in statistical significance. The plot chart illustrates productivity by the deterministic measurement as dependent variables and that by the actual measurement under the conventional system in Fig.3. Fig.4. also shows the plot chart of the identical relationship in Fig.3. in the GPS-based system with $95 \%$ confidence intervals.

As illustrated in Figs.3. and 4., it is concluded that quantified results by four productivity measurements were significantly analyzed within $95 \%$ of confidence intervals in statistics although one outlier was shown in Fig.4.

Consequently, to some extent, the four different

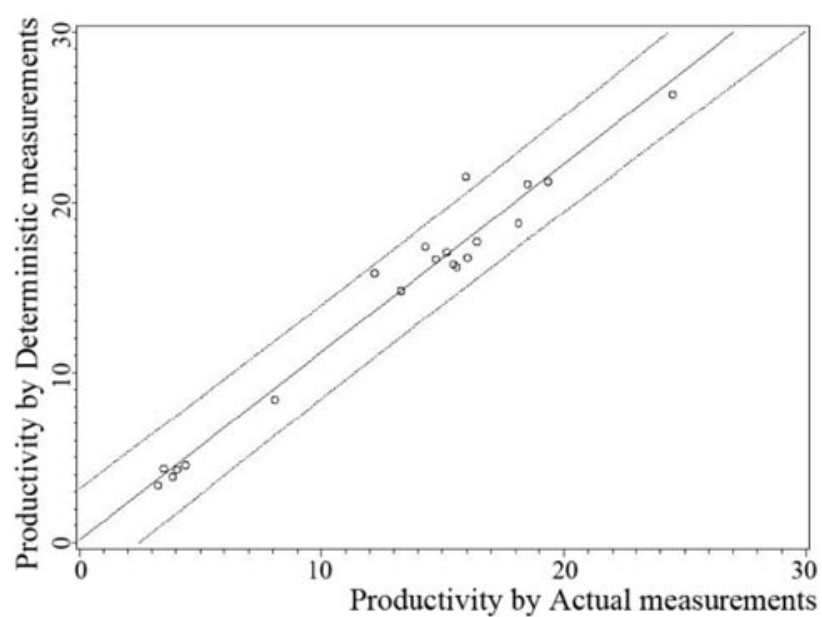

Fig.3. Plot Chart of Productivity by Actual and by Deterministic Measurements in the Conventional System

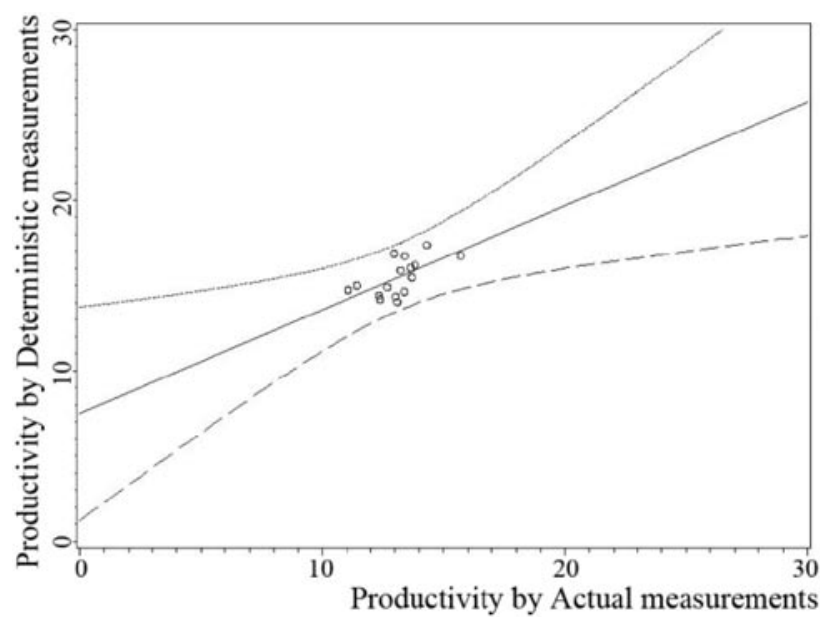

Fig.4. Plot Chart of Productivity by Actual and by Deterministic Measurements in the GPS-based System

productivity measurements provide slightly different results. However, these differences are normally regarded as not significant based on statistical views.

\section{Conclusions and Future Works}

This study is developed based on the previous study by Han and Lee (2008), which presented quantified productivity differences by four different measurements; 1) deterministic model-based measurement, 2) queuing theory-based measurement, 3) simulation-based measurement, and 4) actual measurement. The findings in the previous study were only concerned with application to one operation, that of conventional earthmoving.

This study was carried out to validate the findings of the previous study of another operation. That is, two types of earthmoving, the conventional and the GPS-based system, were selected in order to analyze the quantified differences by four various productivity measurements on different types of operations and to prove whether or not the findings in the previous study are applicable for different types of operations. In 
addition, an analysis of different results of productivity concerning the operation employing the new technology of the GPS-based system compared to the conventional system was revealing.

It is noted that the average comparison rates by each different productivity measurement by the actual measurement, yielded $106.23 \%, 104.81 \%$, and $101.71 \%$, by the deterministic model, the simulation model, and the queuing theory, respectively. In the GPS-based system, the average rates were $113.94 \%$, $108.91 \%$, and $108.15 \%$. These observations verify that the comparison results on a particular operation are available for other operations even if the quantified values are slightly different. These differences are derived from many causes such as distribution of variable times, skill and experience of data collectors, limitations of the queue theory and simulation modeling in practical application, and so on. However, the differences were mostly within $10 \%$ of the range of productivity loss in the deterministic measurement noted by Halpin (2006). Another finding is that deviations of average values of each measurement to the actual measurement in the conventional system were less than those in the GPS-based system. This fact is derived from characteristics of link systems, variance of hauling times and so on. Checking the differences of statistical views also indicated that these were mostly within $95 \%$ of the confidence intervals.

This study will be beneficial for researchers in academia to provide basic guidelines for developing appropriate methods for measuring construction performances by providing several procedures of verification. In the construction industry, the findings of this study allow site engineers or planners to become aware of specific result differences of different measurements by providing numerical comparisons. It will, ultimately, help construction managers or site engineers to predict productivity and to convert it to more realistic values by using methods other than actual measurements.

While this study focused on two operations with different methods, it still reveals a limitation in that application to more various operations may give different results against this study. However, these further studies on other operations would involve serious time and labor-intensive efforts. Deep investigations on effective methodologies for overcoming this limitation are demanded at the next phase.

\section{Acknowledgment}

This work was supported by the INHA UNIVERSITY Research Grant.

\section{References}

1) AbouRizk, S. M. and Halpin, D. W. (1992) Statistical properties of construction duration data. Journal of Construction Engineering and Management, 118(3), pp.525-544.

2) Guo, X. (2007) Continuous-time Markov decision processes with discounted rewards: The case of Polish spaces. Mathematics of Operations Research, 32(1), pp.73-87.

3) Hajjar, D. and AbouRizk, S. (1997) AP2-Earth: A simulation based system for the estimating and planning of earth moving operations. Piscataway: Winter Simulation Conference 1997.

4) Halpin, D. W. (2006) Construction management. 3rd ed. New York: John Wiley \& Sons, Inc.

5) Halpin, D. W. and Riggs, L. S. (1992) Planning and analysis of construction operations. New York: John Wiley \& Sons, Inc.

6) Han, S. (2005) Application modeling of the conventional and the GPS-based earthmoving systems. West Lafayette: Purdue University at West Lafayette.

7) Han, S. and Halpin, D. W. (2005) The use of simulation for productivity estimation based on multiple regression analysis. Piscataway: Winter Simulation Conference 2005.

8) Han, S., and Lee, S. (2008) Quantified comparison and analysis of different productivity measurements. Journal of Asian Architecture and Building Engineering, 7(2), pp.309-316.

9) Han, S., Lee, S., Hong, T., and Chang, H. (2006) Simulation analysis of productivity variation by global positioning system (GPS) implementation in earthmoving operations. Canadian Journal of Civil Engineering, 33(9), pp.1005-1114.

10) Han, S., Hong, T., and Lee, S. (2008) Production prediction of conventional and global positioning system-based earthmoving systems using simulation and multiple regression analysis. Canadian Journal of Civil Engineering, 35(6), pp.574-587.

11) Kannan, G. (1999) A methodology for the development of a production experience database for earthmoving operations using automated data collection. Blacksburg: Virginia Polytechnic Institute and State University at Blacksburg.

12) Koehrsen, C., Sahm, W., and Keefer, C. (2001) GPS-based earthmoving for construction. Manno: First International Symposium DEM 2001.

13) Nichols, H. L. and Day, D. A. (1999) Moving the earth: the workbook of excavation. 4th ed. New York: McGraw-Hill, Inc.

14) Nunnally, S. W. (2000) Managing construction equipment. 2nd ed. Upper Saddle River: Prentice-Hall, Inc.

15) Schaufelberger, J. E. (1999) Construction equipment management. Upper Saddle River: Prentice-Hall, Inc.

16) Schexnayder, C. J., and Mayo, R. E. (2004) Construction management fundamentals. New York: McGraw-Hill, Inc.

17) Wang, S. and Halpin, D. W. (2004) Simulation experiment for improving construction processes. Piscataway: Winter Simulation Conference 2004. 